Bryn Mawr College

Scholarship, Research, and Creative Work at Bryn Mawr

College

Psychology Faculty Research and Scholarship

Psychology

2015

\title{
Measuring emotion regulation and emotional expression in breast cancer patients: A systematic review
}

Tânia Brandão

Rita Tavares

Marc S. Schulz

Bryn Mawr College,mschulz@brynmawr.edu

Paula Mena Matos

Let us know how access to this document benefits you.

Follow this and additional works at: http://repository.brynmawr.edu/psych_pubs

Part of the Psychology Commons

\section{Custom Citation}

Brandão, T., Tavares, R., Schulz, M.S. \& Matos, P.M., "Measuring emotion regulation and emotional expression in breast cancer patients: A systematic review," Clinical Psychology Review 43 (2015): 114-127.

This paper is posted at Scholarship, Research, and Creative Work at Bryn Mawr College. http://repository.brynmawr.edu/psych_pubs/39

For more information, please contact repository@brynmawr.edu. 


\section{Accepted Manuscript}

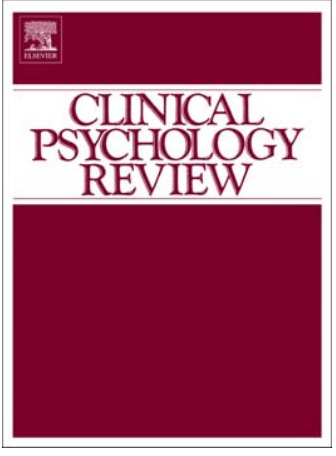

Measuring emotion regulation and emotional expression in breast cancer patients: A systematic review

Tânia Brandão, Rita Tavares, Marc S. Schulz, Paula Mena Matos

PII:

S0272-7358(15)00137-3

DOI:

doi: 10.1016/j.cpr.2015.10.002

Reference:

CPR 1474

To appear in: $\quad$ Clinical Psychology Review

Received date: 18 March 2015

Revised date: $\quad 25$ August 2015

Accepted date: 16 October 2015

Please cite this article as: Brandão, T., Tavares, R., Schulz, M.S. \& Matos, P.M., Measuring emotion regulation and emotional expression in breast cancer patients: A systematic review, Clinical Psychology Review (2015), doi: 10.1016/j.cpr.2015.10.002

This is a PDF file of an unedited manuscript that has been accepted for publication. As a service to our customers we are providing this early version of the manuscript. The manuscript will undergo copyediting, typesetting, and review of the resulting proof before it is published in its final form. Please note that during the production process errors may be discovered which could affect the content, and all legal disclaimers that apply to the journal pertain. 


\title{
Measuring emotion regulation and emotional expression in breast cancer patients: A
}

\section{systematic review}

\author{
Tânia Brandão ${ }^{\mathrm{a}}$, Rita Tavares ${ }^{\mathrm{a}}$, Marc S. Schulz ${ }^{\mathrm{b}}$, Paula Mena Matos ${ }^{\mathrm{a}, *}$ \\ ${ }^{a}$ Faculty of Psychology and Education, University of Porto; Center for Psychology at University \\ of Porto; Porto, Portugal \\ ${ }^{b}$ Department of Psychology, Bryn Mawr College, Pennsylvania, USA.
}

*Corresponding author contact information:

Dr. Paula Mena Matos

Rua Alfredo Allen

4200-135 Porto

Portugal

Telephone number +351226079700

Fax +351226079 725

Email: pmmatos@fpce.up.pt

The important role of emotion regulation and expression in adaptation to breast cancer is now widely recognized. Studies have shown that optimal emotion regulation strategies, including less constrained emotional expression, are associated with better adaptation. Our objective was to systematically review measures used to assess the way women with breast cancer regulate their emotions. This systematic review was conducted in accordance with PRISMA guidelines. Nine different databases were searched. Data were independently extracted and assessed by two researchers. English-language articles that used at least one instrument to measure strategies to regulate emotions in women with breast cancer were included. Of 679 abstracts identified 59 studies were deemed eligible for inclusion. Studies were coded regarding their objectives, methods, and results. We identified 16 instruments used to measure strategies of emotion regulation and expression. The most frequently employed instrument was the Courtauld 
Emotional Control Scale. Few psychometric proprieties other than internal consistency were reported for most instruments. Many studies did not include important information regarding descriptive characteristics and psychometric proprieties of the instruments used. The instruments used tap different aspects of emotion regulation. Specific instruments should be explored further with regard to content, validity, and reliability in the context of breast cancer.

Keywords: systematic review, breast cancer, emotion regulation, emotional expression, measurement

\section{Introduction}

In the context of breast cancer, the regulation of emotion, especially emotional expression, has been linked to patients' adaptation and well-being. The diagnosis and treatment of breast cancer are stressful experiences that can evoke a variety of negative emotions and broader affective experiences such as anxiety, sadness, anger, guilt, and fear of death and suffering (Adler \& Page, 2008). It is now widely recognized that the way women regulate and express their emotions can influence not only their psychological adaptation but also their endocrine and immune functioning, which play a role in patients' quality of life and cancer prognosis (Austenfeld \& Stanton, 2004; Giese-Davis \& Spiegel, 2003; Giese-Davis, DiMiceli, Sephton, \& Spiegel, 2006; Gross, 1989; Watson, Greer, \& Rowden, 1991). More specifically, women with breast cancer who reported using generally less adaptive strategies to regulate or express their emotions (e.g., suppression or inhibition) also reported more emotional distress, depressive symptoms, anxiety, and lower quality of life and physical health (Classen et al., 1996; Iwamitsu et al., 2005; Lieberman \& Goldstein, 2006; Low et al., 2006; Stanton et al., 2000; Wang et al., 
2014). There is also evidence that repressive emotional styles are linked to physiological difficulties such as problematic cortisol regulation and higher blood pressure (Giese-Davis et al., 2004; 2008).

A wide range of self-report measures have been developed to assess emotion regulation and related constructs (e.g., the Emotion Regulation Questionnaire; the Cognitive Emotion Regulation Questionnaire; the Emotional Expressivity Scale). However, decisions about which measure to use are challenging given the diverse conceptualizations and elements of emotion regulation. The lack of agreement among experts regarding the definition and conceptualization of emotion regulation has led to the development of a large number and variety of measures to assess this construct. While each measure may be identified as assessing aspects of emotion regulation, they emphasize different constructs depending on the authors' conceptualization of emotion regulation and its key components. For instance, some experts argue that one's ability to identify emotions is a key feature of emotion regulation (e.g., Gratz \& Roemer, 2004; Taylor, 1994). Others focus on one's tendency to directly engage with and express negative emotions as key elements of emotion regulation (e.g., Gross \& John, 2003; Watson \& Greer, 1983).

A process-oriented view of emotion regulation has begun to dominate the field that emphasizes multiple kinds of regulatory strategies. Thompson (1994) defined emotion regulation as "the extrinsic and intrinsic processes responsible for monitoring, evaluating, and modifying emotional reactions, especially their intensive and temporal features, to accomplish one's goals" (p. 27-28). Gross (1998), like Thompson, focuses on emotion regulation as a process in his influential work. He defines emotion regulation as "the process by which individuals influence which emotions they have, when they have them, and how they experience and express these emotions" (p. 275). Campos, Frankel, and Camras (2004) offer a complementary view, defining 
emotion regulation as "the modification of any process in the system that generates emotion or its manifestation in behavior" (p. 380). For the purposes of this review, it is notable that each of these process definitions highlights the modulation of emotional expression as a key component of emotion regulation.

Although emotion regulation and coping are considered closely related constructs (Schulz \& Lazarus, 2012), theorists have also noted differences in these constructs. Compas et al. (2013) note that both coping and emotion regulation are self-regulatory processes that include controlled and purposeful efforts that can change over time. Coping can include efforts to regulate emotion when an individual is under stress. In terms of important differences, Compas et al. (2013) emphasized the fact that emotion regulation is commonly understood to include conscious and unconscious processes while coping has more commonly included only controlled responses. More generally, coping refers to responses to stress while emotion regulation involves regulatory efforts engaged in a wider range of situations and affective experiences.

In our view, a cognitive-mediational conceptualization of emotion (Lazarus, 1991) is a useful framework for defining emotion regulation. From this perspective, emotion regulation is conceptualized as the process by which individuals modulate any of the subcomponents of the emotion system, including elements that might contribute to emotion, such as an individual's personal appraisal of the situation, and the response tendencies generated by emotions (i.e., feelings, expressive behaviors, and physiological reactions) (Schulz \& Lazarus, 2012). Emotion regulatory processes involve three main mechanisms: input regulation (i.e., strategies used to alter factors that shape the generation of emotion, such as attentional deployment), reappraisal (i.e., strategies used to change the meaning of an encounter, such as viewing a situation in a more positive light), and output regulation (i.e., strategies used to regulate emotional responses 
including expression of emotion) (Gross, 2001; Schulz \& Lazarus, 2012). Emotion regulatory processes can be planful, deliberate, and rational, but they can also unfold out of consciousness. Coping is a set of cognitive and behavioral efforts that is initiated by an appraisal of a particular situation as having personal meaning. Coping efforts are guided by an individual's objectives in that situation; these objectives are likely to include a desire to regulation emotions in a particular manner (Schulz \& Lazarus, 2012). In this perspective, strategies of emotion regulation can be understood as part of the larger coping efforts used to respond to the stress associated with the diagnosis and experience of breast cancer.

The present study aims to systematically review the measures currently used to assess strategies to regulate emotions within the context of breast cancer. The intent is to summarize the main characteristics of these measures and evaluate their psychometric properties in order to facilitate researchers' choices about which scales to use to assess these strategies in both clinical settings and in research studies. Most of these measures were not developed specifically for use with women with breast cancer. Thus, it is important to examine evidence for their reliability and utility in studying adaptation to breast cancer, particularly given the emphasis on emotion processes in adaptation to breast cancer. As a number of investigators have noted, the adaptive potential of particular emotion regulatory processes is likely to depend on the particular context in which these processes are being used (Bonanno \& Burton, 2013; Schulz \& Lazarus, 2012). Similarly, the reliability and validity of measures of emotion regulation may vary by context. The main research questions that guide this review are: (1) What instruments have been used to assess strategies used by breast cancer patients to regulate emotions? (2) What is the evidence for the reliability and validity of these instruments in research on breast cancer? (3) What are the main findings regarding the consequences of using specific strategies to regulate emotions for 
breast cancer patients? To our knowledge this is the first systematic review addressing these questions.

\section{Method}

This systematic review was conducted in accordance with PRISMA (Preferred Reporting Items for Systematic Reviews and Meta-Analyses) guidelines (Moher, Liberati, Tetzlaff, Altman, The PRISMA Group, 2009).

\section{Eligibility criteria}

Full-text research articles published in English that included at least one instrument to measure dimensions of emotion regulation or emotional expression in women with breast cancer were eligible. Exclusion criteria included: (1) non-English-language articles; (2) articles not measuring aspects of emotion regulation or emotional expression; (3) articles that were not specific to breast cancer (e.g., articles were excluded if they included other types of cancer or other diseases or participants without medically diagnosed breast cancer, such as studies of women with genetic risk to develop breast cancer); (4) literature reviews, books, unpublished articles and doctoral theses, commentaries, abstracts of conferences and congresses, case-reports, and qualitative studies; (5) articles using exclusively general personality questionnaires; and (6) validation studies.

\section{Search strategy}


Database searches were conducted from inception to September 2014 in Academic Search Complete, CINAHL plus, ERIC, MedicLatina, MEDLINE, PsycARTICLES, PsycCRITIQUES, Psychology and Behavioral Sciences Collection, and PsycINFO. Searches in these databases were supplemented by additional manual searching in Google. The key search terms used were: breast cancer OR mastectomy AND emotion* regulation, OR emotion* expression OR emotion* control OR emotion* self-efficacy OR emotion* suppression OR affect regulation. After duplicates were removed, titles and abstracts were assessed for eligibility independently by two researchers. Disagreements were discussed and resolved by consensus.

\section{Results}

The results are presented in three sections: (1) a description of the included studies, (2) a description of the instruments used to measure emotion regulation strategies, and (3) a description of main findings presented by the included studies regarding dimensions of emotion regulation.

\section{Description of the included studies}

A total of 679 articles were identified: 201 from PsycInfo, 188 from MEDLINE Search Complete, 135 from Academic Search Complete, 95 from CINAHL Plus, 41 from Psychology and Behavioural Sciences Collection, 12 from PsycArticles, 2 from ERIC, 1 from MedicLatina, and 6 from manual searching. After duplicate studies were removed, 345 studies remained and the abstracts were carefully screened and evaluated. From these, 277 were excluded (28 were 
non-English articles; 120 did not measure emotion regulation or emotion expression; 29 included other types of cancer or diseases; 93 were literature reviews, qualitative studies or abstracts of conferences or congresses; 4 measured personality traits, and 3 were exclusively validation studies) (see flow chart in Figure 1).

A final 68 studies were retrieved for full text screening. From these 9 were excluded because, after further review, they were found to not include a measure to assess emotion regulation or emotional expression. A total of 59 studies were, therefore, included in this review.

(Insert Figure 1 about here)

The majority of studies were longitudinal in nature $(\mathrm{n}=24 ; 41 \%)$ followed by randomized controlled trials or (quasi) experimental designs $(n=16 ; 27 \%)$. The remaining were cross-sectional $(n=19 ; 32 \%)$. Studies were most commonly conducted in the USA $(n=23$; $39 \%$ ), but there was a wide variety of other locales (Japan, Spain, Netherlands, New Zealand, China, Israel, France, Canada, Italy, Finland, Greece, Norway, United Kingdom, Portugal, Belgium, and Denmark). Data were gathered from 8,181 participants (sample sizes ranged from 22 to 847 participants) with a mean age of 64.62 years. All studies included women with BC stage I-IV (some studies also included healthy controls or women with benign tumors). A detailed description of all included studies (characteristics and main results) is shown in Supplementary material available online. 


\section{Description of the instruments used to measure emotion regulation strategies}

Among the reviewed studies, we found 16 different instruments used for measuring coping strategies that primarily involved the regulation of emotions in the context of breast cancer. Table 1 summarizes information about the instruments' characteristics. The most frequently reported measure was the Courtauld Emotional Control Scale (Watson \& Greer, 1983; $\mathrm{n}=32$ studies; $56 \%$ ) followed by the Emotional Approach Coping Scale (Stanton, Kirk, Cameron, \& Danoff-Burg, 2000; $\mathrm{n}=7$ studies; $12 \%$ ), the Toronto Alexithymia Scale (Bagby, Parker, \& Taylor, 1994; $\mathrm{n}=6$ studies; 11\%), the Weinberg Adjustment Inventory - Short Form (Weinberger, 1990; $\mathrm{n}=6$ studies; 11\%), the Stanford Emotional Self-efficacy Scale -Cancer (Giese-Davis et al., 2004; $\mathrm{n}=5$ studies; 9\%), the Cancer Behavior Inventory (Merluzzi, 2001; $\mathrm{n}$ $=3$ studies; 5\%), the Control of Feeling Scale (Benjamin \& Friedrich, 1991; $\mathrm{n}=3$ studies; 5\%); the Rationality/Emotional Defensiveness (Spielberger, 1988; $\mathrm{n}=3$ studies; 5\%), the Ambivalence over Emotional Expression Questionnaire (King \& Emmons, 1990; $\mathrm{n}=2$ studies; 4\%), the Cognitive Emotion Regulation Questionnaire (Garnefski, Kraaij, \& Spinhoven, 2002; n $=2$ studies; 4\%), and the Emotional Expressiveness Questionnaire (King \& Emmons, 1990; $\mathrm{n}=$ 2 studies; 4\%). A number of relevant scales were used only once: the Berkeley Expressivity Questionnaire (Gross \& John, 1995), the COPE (Carver, Scheier, \& Weintraub, 1989); the Emotion Self-Disclosure Scale (Snell, Miller, \& Beck, 1988), the Marlowe Crowne Social Desirability Scale (Crowne \& Marlowe, 1964), and the Ways of Coping Questionnaire modified (Reynolds et al., 2000). All measures were self-report. Details about each of the 16 measures follow. We also briefly present data on the extent of use and the psychometric properties of these instruments in studies that did not involve breast cancer populations. 
(Insert table 1 about here)

\section{The Courtauld Emotional Control Scale (CECS)}

The CECS was developed by Watson and Greer (1983) as a questionnaire to measure emotional control, a tendency to control or suppress the expression of negative emotions when communicating to others. It evaluates how individuals control their feelings of anger, anxiety, and depressed mood in daily experiences. It comprises 21 items that can be organized into 3 subscales: anger control (7 items; e.g., "When I feel angry I keep quiet"), anxiety control (7 items; e.g., "When I feel afraid I let others see how I feel”), and depressed mood control (7 items; e.g., "When I feel unhappy I refuse to do anything about it") scored on a Likert-type scale from 1 (almost never) to 4 (almost always). A majority of studies have used the CECS as an overall scale to measure "control of emotions" or "suppression of emotions". It has been the most common scale used to evaluate emotion control in the context of breast cancer and presented good internal consistency with $\alpha$ 's ranging from .83 to .95 (Ando et al., 2011; Andreu et al., 2012; Cameron et al., 2007; Classen et al., 1996; Giese-Davis et al., 2002, 2006b; Iwamistu et al., 2003, 2005a, 2005b; Schlatter et al., 2010) and reliability with 3-4 month testretest reliability $=.95$ (Schlatter et al., 2010). The CECS has been used with a wide variety of populations (see Table 1 for data on the number of publications describing the use of the CECS and all the measures reviewed) and has shown similar levels of reliability. In a sample of patients with different types of cancer the scale showed good internal consistency $(\alpha=.96)$ (Cohen, 2013). With other medical populations (e.g., HIV patients) internal consistency was also found to be good (e.g., $\alpha=.82$ ) (Lagana et al., 2002). 


\section{The Emotional Approach Coping Scale (EACS)}

The EACS (Stanton, Kirk, Cameron, and Danoff-Burg, 2000) uses a subset of the items from the Brief-COPE (Carver, 1997) to assess coping through emotional approach, which involves acknowledging, understanding, and expressing emotions (Austenfeld \& Stanton, 2004). It comprises 2 subscales: emotional expression defined as active verbal and/or nonverbal efforts to communicate or represent one's emotional experience (4 items; e.g., "I allow myself to express my emotions") and emotional processing defined as an active efforts to acknowledge, explore meanings, and come to an understanding of one's emotions (4 items; e.g., "I acknowledge my emotions").

The EACS is scored on a Likert-type scale from 1 (usually do not do this at all) to 4 (usually do this a lot). Studies reported good internal consistency for the emotional expression subscale ( $\alpha$ 's ranged from .78 to .91) (Batenburg et al., 2014; Cohen et al., 2011; Manne et al., 2004, 2007; Puig et al., 2006; Stanton et al., 2000, 2012) and good test-retest reliability $(r=.72)$ (Puig et al., 2006). The emotional processing subscale was found to have low internal consistency in two studies ( $\alpha=.32$ and .63; Manne et al., 2004; Stanton et al., 2012, respectively) but the remaining studies reported good internal consistency ( $\alpha$ 's range from .69 to .91) (Batenburg et al., 2014; Cohen et al., 2011; Manne et al., 2007; Puig et al., 2006; Stanton et al., 2000) and good test-retest reliability when reported $(r=.73)$ (Puig et al., 2006). The EACS has been used in other contexts and has demonstrated good internal consistency with other medical samples (e.g., $\alpha=.92$ for patients with myofascial pain; $\alpha=.85$ for patients with 
fibromyalgia) (Geenen, der Linden, Lumley, Bijlsma, \& van Middendorp, 2012; Smith, Lumley, \& Longo, 2002)

3. The Toronto Alexithymia Scale (TAS)

The TAS was developed by Bagby, Parker, and Taylor (1994) to measure alexithymia or difficulty in experiencing, identifying, describing and verbally communicating one's feelings to others. It is composed of 20 items with 3 subscales: difficulty identifying feelings ( 7 items; e.g. "I am often confused about what emotion I am feeling"), difficulty describing feelings (5 items; e.g., "I am able to describe my feelings easily"), and externally oriented thinking that is conceptualized as a tendency to focus one's attention externally as a way to avoid feelings ( 8 items; e.g., "I prefer to analyze problems rather than just describe them"). Each item is scored on a 5-point Likert-type scale from 1 (completely disagree) to 5 (completely agree). Two studies reported data regarding internal consistency ( $\alpha$ 's range between .81 and .95; Jensen-Johansen et al., 2013; Servaes et al., 1999). The TAS is widely used measure outside the context of breast cancer and has shown strong psychometric properties in those diverse contexts. The term Toronto Alexithymia Scale showed that it appears in 1227 publications according to the PsychInfo database.

4. The Weinberger Adjustment Inventory - Short Form (WAI-SF)

The WAI-SF was developed by Weinberger (1990) and is composed of 3 subscales (distress - 12 items; restraint - 12 items; and repressive-defensiveness -11 items). The studies 
included here have used the repressive-defensiveness subscale to tap emotional repression. Repression is conceptualized as an unconscious tendency to avoid remembering or bringing into awareness disturbing feelings or unpleasant cognitions (Giese-Davis et al., 2002). The WAI-SF measures repression with eleven items (e.g., "I have done things that were not right and felt sorry about it later), scored on a Likert-type scale from 1 (false) to 5 (true).

Four studies reported data regarding internal consistency ( $\alpha$ 's range from .69 to .73) (Giese-Davis et al., 2002, 2006; Servaes et al., 1999; Tamagawa et al., 2013). A previous study found good one-year test-retest reliability $(r=.75)$ (Giese-Davis \& Spiegel, 2001). The WAI-SF has been used in other populations but data on its psychometric properties in these contexts are not consistently reported.

5. The Stanford Emotional Self-Efficacy Scale - Cancer (SESES)

The SESES was developed by Giese-Davis et al. (2004) to measure emotion regulation and expression in patients coping with cancer. It is based on emotion regulation theories that emphasize the importance disclosing and communicating emotions, regulating emotions to be able to focus on the present, and tolerance of affect associated with death and dying concerns (Giese-Davis et al., 2004). This measure is composed of 15 items that comprise 3 subscales: communicating emotions in relationships (5 items; e.g., "Let my friends know when I am angry because of something they did"), focusing on the present moment (5 items; e.g., "Focus my full attention on one thing at a time"), and confronting death and dying issues (5 items; e.g., "Directly consider the thought that I might die."). This scale measures perceived self-efficacy around one's ability to manage emotions in these domains; Giese-Davis et al., 2004). It is scored 
on a 100-point Likert-type scale ranging from 0 (not at all confident) to 100 (completely confident) in increments of 10 .

The initial evaluation of psychometric proprieties was performed with a breast cancer sample (Giese-Davis et al., 2004). The authors found good internal consistency (total score $\alpha$ $=.89$; communicating emotions $\alpha=.82$; focusing on present $\alpha=.79$; and confronting death $\alpha$ $=.80$ ) and good three month test-retest reliabilities for the total score and for two of the three subscales (total score $r=.69$; communicating emotions $r=.71$; and confronting death $r=.67$ ). The exception is for the subscale focusing on present, which had lower test-retest reliability (r $=.57)$. Concurrent validity was assessed by comparing the SESES with the CECS. Results showed a medium to large negative correlation between suppression of emotions (CECS) and emotional self-efficacy (SESES). Evidence for predictive validity and generalizability were also presented (for more details see Giese-Davis et al., 2004). The subsequent studies using this scale found good internal consistency for each subscale (communicating emotions $\alpha=.81$, focusing in the moment $\alpha=.75$, and confronting death and dying $\alpha=.82$; Giese-Davis et al., 2002) and for the total score ( $\alpha$ 's range from .73 to .90) (Giese-Davis et al., 2002; Han et al., 2005; Palesh et al., 2006). The scale also maintained good test-retest reliability (r's range between .80 and .95 ) (Giese-Davis et al., 2002). In a study of patients with prostate cancer the scale also presented good internal consistency $(\alpha=.89)$ (Hoyt, Stanton, Irwin, \& Thomas, 2013). No other studies were found using this scale.

6. The Cancer Behavior Inventory (CBI) 
The CBI was developed by Merluzzi and Martinez Sanchez (1997) to assess self-efficacy for coping with cancer. It is composed of 51 items divided into 6 subscales (affective regulation; maintenance of activity and independence; seeking and understanding medical information; stress management; coping with treatment-related side-effects; accepting cancer/maintaining positive attitude; seeking support). The affective regulation subscale aims to assess one's sense of confidence in effectively regulating and expressing negative feelings (5 items; e.g., "Expressing feelings about cancer"; "Sharing my worries or concerns with others"). Items are scored on a 9-point scale ranging from 1 (not all confident) to 9 (totally confident). One study reported internal consistency for the total scale $(\alpha=.95)$ (Collie et al., 2007). The CBI has been used with other oncology populations and shown good internal consistency ( $\alpha$ 's range between .84 and .88) (Heitzmann et al., 2011; Zachariae et al., 2003).

\section{The Control of Feeling Scale (CFS)}

The CFS (also referred to as the Acceptance of Emotions Scale) was adapted by Wheis et al. (2000) based on the Structural Analysis of Social Behavior Intrex developed by Benjamin and Friedrich (1991). It is a 13-item scale used to measure how individuals view their emotions, how they relate to them (including whether they accept them as is or try to change them), and how they control them (e.g., "I try very hard to make my feelings as ideal as possible"). All items are scored on a 100-point Likert-type scale ranging from 0 (never/ not at all) to 100 (always/ perfectly) in increments of 10 . The instrument presented good internal consistency $(\alpha=.92)$ (Politi, Enright, \& Wheis, 2007) and test-retest reliability $(r=.58)$ (Wheis, Enright, \& Simmens, 2008). No other studies were found using this instrument outside of the context of breast cancer. 
8. The Rationality/Emotional Defensiveness (R/ED)

The R/ED was developed by Spielberger (1988) to measure defensive attempts to minimize emotional experience or expression. It is a 12 -item scale with each item scored on a 4point Likert-type scale ranging from 0 (almost never) to 4 (almost always). The R/ED has 2 subscales: emotional defensiveness (or anti-emotionality), defined as a tendency to use logic and reason to avoid or minimize upsetting emotions in interpersonal contexts (6 items; e.g., "I try to understand other people even if I do not like them), and rationality, defined as a tendency to use logic and reason as a general approach to cope with the environment (6 items; e.g., "I try to do what is sensible and logical" (Fernandez-Ballesteros, Zamarrón, Ruiz, Sebastian, \& Spielberger, 1997; Letho et al., 2006).

For the one study that reported data regarding internal consistency, $\alpha$ 's ranged from .81 to .88 , and test-retest reliability was good, $r=.81$ (Fernandez-Ballesteros et al., 1998). The R/ED is not a widely used scale. A search of the PsychInfo database using the term "rationality emotional defensiveness" showed that it appears only in 19 publications. It has demonstrated adequate internal consistency when used with other populations than breast cancer (e.g., $\alpha=.77$ in a sample of university students (Ritz \& Dahme, 1996) and $\alpha=.76$ in chronic kidney disease (Kaltsouda et al., 2011)).

9. The Ambivalence over Emotional Expression Questionnaire (AEEQ) 
The AEEQ was developed by King and Emmons (1990) to assess ambivalence or worries about expressing emotions. It is a one-dimensional scale and is composed of 28 items (e.g., "I want to express my emotions honestly but I am afraid that it may cause me embarrassment or hurt"). Items are scored on a 5-point Likert-type scale ranging from 0 (never) to 4 (always). Two studies used the AEEQ and showed good internal consistency $(\alpha=.87$ and .93) (Algoe et al., 2011; Servaes et al., 1999). While not widely used, good internal consistencies have also been found for the AEEQ in studies with other populations (e.g., $\alpha=.95$ for young adults and $\alpha=.86$ for undergraduate students) (Niles, Haltom, Mulvenna, Lieberman, \& Stanton, 2014; Spokas, Luterek, \& Heimberg, 2009).

10. The Cognitive Emotion Regulation Questionnaire (CERQ)

The CERQ is a multidimensional questionnaire developed by Garnefski et al. (2002) that measures cognitive components of emotion regulation, specifically, the cognitive coping strategies that individuals use to deal with negative or stressful events. The CERQ consists of 36 items organized into 9 subscales: self-blame (4 items; e.g., "I feel that I am the one who is responsible for what has happened"), acceptance (4 items; e.g., "I think that I must learn to live with it"), rumination (4 items; e.g., "I dwell upon the feelings the situation has evoked in me"), positive refocusing ( 4 items; e.g., "I think of something nice instead of what has happened"), refocus on planning (4 items; e.g., "I think about how I can best cope with the situation"), positive reappraisal (4 items; e.g., "I think that I can become a stronger person as a result of what has happened"), putting into perspective (4 items; e.g., "I think that it all could have been much worse"), catastrophizing (4 items; e.g., "I keep thinking about how terrible it is what I have 
experienced"), and other-blame (4 items; e.g., "I feel that others are responsible for what has happened"). All items are scored on a 5-point Likert-type scale ranging from 1 (almost never) to 5 (almost always). Two studies reported internal consistency information (in Hamana-Raz et al., $2012 \alpha$ ranged from .59 to .84; in Wang et al., $2014 \alpha$ ranged from .75 to .96). Wang et al. (2014) also reported the results of a confirmatory factor analysis with the same sample that suggested good fit indices for the model with 9 subscales.

The CERQ shows similar internal consistencies in different populations (early adolescents, late adolescents, adults, elderly people, and psychiatric patients) with $\alpha$ 's ranging from .68 to .86 (Garnefski et al., 2002).

11. The Emotional Expressiveness Questionnaire (EEQ)

The EEQ is a measure developed by King and Emmons (1990) that aims to measure overall emotional expressiveness or the tendency to express emotional responses in ways that can be observable by others. It is a one-dimensional scale composed of 16 items (e.g., "When I am angry people around me usually know") scored on a 7-point Likert-type scale ranging from 1 (strongly disagree) to 7 (strongly agree). One study reported information regarding internal consistency $(\alpha=.80)$ (Servaes et al., 1999). Similar reliabilities have been found in other studies with different populations (e.g., $\alpha=.74$ in a sample of college students; $\alpha=.77$ in a sample of young adults) (Barr, Kahn, \& Schneider, 2008; Niles et al., 2013.

12. The Berkeley Expressivity Questionnaire (BEQ) 
The Berkeley Expressivity Questionnaire was developed by Gross and John (1995) to measure emotional expressivity. It is a 16-item questionnaire with 3 subscales: negative expressivity, which taps the tendency to express negative emotions (6 items; e.g., "Whenever I feel negative emotions, people can easily see exactly what I am feeling"), positive expressivity, which taps the tendency to express positive emotions (4 items; e.g., "When I feel happy, my feelings show"), and impulse strength, which taps the intensity of how one experiences feeling states (6 items; e.g., "I experience my emotions very strongly"). Items are scored on a 7-point Likert-type scale ranging from 1 (strongly disagree) to 7 (strongly agree). One study found good internal consistency $(\alpha>.94)$ and two-three month test-retest reliability $(r=.86)$ (Stanton et al., 2012). Similarly strong reliabilities have been reported for the BEQ in studies with populations (e.g., undergraduate students) other than breast cancer patients (e.g., Gross \& John, 1997).

\section{The COPE Inventory}

The COPE Inventory was developed by Carver, Scheier, and Weintraub (1989) to measure coping strategies. It is widely used and is composed of 60 items, divided into two major categories: emotion-focused strategies (including emotional expression (4 items; e.g., "I get upset and let my emotions out"), seeking social support (4 items; e.g., "I try to get emotional support from friends and relatives"), positive reinterpretation (4 items; e.g., "I look for something good in what is happening"), acceptance (4 items; e.g., "I get used to the idea that it happened"), turning to religion (4 items; e.g., "I put my trust in God"), denial (4 items; e.g., "I say to myself this is not real"), behavioral disengagement (4 items; e.g., "I admit to myself that I cannot deal with it and quit trying"), distraction (4 items; e.g., "I turn to work or other substitute 
activities to take my mind off things"), drug and alcohol abuse (4 items; e.g., "I use alcohol or drugs to make myself feel better"), and humor (4 items; e.g., "I laugh about the situation")) and problem-focused strategies (including active coping (4 items; e.g., "I concentrate my efforts on doing something about it"), planning (4 items; e.g., "I make a plan of action"), suppression of competing activities (4 items; e.g., "I keep myself from getting distracted by other thoughts or activities"), restraint (4 items; e.g., "I restrain myself from doing anything too quickly"), and information seeking (4 items; e.g., "I try to get advice from someone about what to do")). Participants respond to items on a 4-point Likert-type scale ranging from 1 (I haven't been doing this at all) to 4 (I've been doing this a lot).

Internal consistency for ten subscales ranged between .54 and .98 with two falling below .60 (the following 5 subscales were not included: restraint, suppression of competing activities, religion, drug and alcohol use, and behavioral disengagement) (Roussi et al., 2007). Similar weak reliabilities have been found in other studies for specific subscales, including original Carver's study, with some subscales showing low internal consistency $(\alpha$ 's $<.65)$ (Carver et al., 1989). The COPE Inventory, however, is a widely used measure outside the context of breast cancer. A search of the PsychInfo database using the term COPE inventory showed that it appears in 233 publications.

\section{The Emotion Self-Disclosure Scale (ESDS)}

The ESDS was developed by Snell, Miller, and Belk (1988) to measure people's tendency to be open and to express their emotions to a friend, a romantic partner, or a physician/ therapist. It has 40 items that can be broken down into 8 subscales (each one composed of 5 items) that 
assess the extent to which a person has discussed specific types of feelings and emotions with others: feelings of depression (e.g., "Time when you felt depressed"), happiness (e.g., "Time when you felt cheerful”), jealousy (e.g., “Time when you felt possessive”), anxiety (e.g., “Time when you felt troubled"), anger (e.g., "Time when you felt infuriated"), calmness (e.g., "Time when you felt quiet"), apathy (e.g., "Time when you felt indifferent), and fear (e.g., "Time when you felt frightened"). Servaes et al. (1999) used a short-version of the ESDS with 17 items. Internal consistency for the overall scale was good $(\alpha=.93)$. While not widely used, when employed with other populations, this scale also presented good internal consistencies ( $\alpha$ 's ranging between .70 and .89 in a sample of college students) (Barr et al., 2008).

15. The Marlowe Crowne Social Desirability Scale (MCSDS)

The MCSDS was developed by Crowne and Marlowe (1964) to measure social desirability independent of psychopathology. It has also been used as a measure of emotional constraint that is intended to capture a defensive tendency to avoid affect that a person believes is not socially desirable (Wheis et al., 2000). It is a one-dimensional scale comprised of 33 items (e.g., "I almost never feel the urge to tell someone off") scored on a true-false format. It has good internal consistency $(\mathrm{KR} 20=.80)$ and adequate one month test-retest reliability $(r=.88)$ (Wheis et al., 2000). The MCSDS is not a widely used measure in the context of cancer but it has been used widely with other populations. Studies with other populations typically yield good reliabilities (e.g., $\alpha>$.70) (Brajša-Žganec, Ivanović, \& Lipovčan, 2011; Miotto \& Preti, 2008). 
The WCQ-M, developed by Reynolds et al. (2000) is a modified version of the widely used Ways of Coping Questionnaire from Folkman and Lazarus (1980). It is used to measure coping strategies adopted by individuals when confronting a stressful situation. It is composed of 28 items that break down into 7 subscales: expressing emotion ( 3 items; e.g., "Talk to someone about how you are feeling"), suppressing emotions (3 items: e.g., “Try to keep feelings to yourself”), wishful thinking (5 items; e.g., "Wish situation would go away or be over with”), problem-solving (4 items; e.g., "Learn as much as you can in order to better understand"), positive reappraisal (5 items; e.g., "Remind yourself how much worse things could be"), avoidance (5 items; e.g., "Go on as if everything will be okay"), and escapism (3 items; e.g., "Try to get away from it by doing relaxing things"). Items are scored on a 4-point Likert-type scale ranging from 0 (does not apply or not used) to 3 (used a great deal). Information regarding psychometric proprieties of this modified version was not available in the study that employed this scale (Reynolds et al., 2002). The non-modified version of the WCQ is widely used in studies of cancer patients and in other contexts. These studies point to poor internal consistency in some of the WCQ subscales (e.g., $\alpha$ 's $<.70$ for cancer patients or survivors of suicide for confrontive coping, distancing and accepting responsibility, dimensions of the non-modified version of the WCQ) (Lundqvist \& Ahlstrfm, 2006; Terhorst \& Mitchell, 2012). A search of the PsychInfo database using the term Ways of Coping Questionnaire showed that it appears in 491 publications.

Some studies identified for this review used more than one instrument, so limited information regarding intercorrelations between instruments is available. Graves et al. (2005) analyzed the correlation between four of the instruments included here (the CECS, the TAS, the EEQ, and the R/ED). They found that the TAS was positively correlated with the CECS $(r=.46$, 
$\mathrm{p}<.01)$ and negatively correlated with the EEQ $(\mathrm{r}=-.41, \mathrm{p}<.01)$. The moderate to large magnitude of the correlations suggests that the instruments are tapping similar but not overlapping constructs. Stanton et al. (2012) found a correlation between the BEQ and the EACS. The BEQ was positively correlated with both emotional processing $(r=.21, p<.05)$ and emotional expression $(r=.44, p<.001)$.

As would be expected, Giese-Davis et al. $(2002,2004)$ found significant negative correlations between the CECS and the SESES-C $(r=-.55, p<.01, r=-.43, p<.001)$. In the 2002 study neither the CECS nor the SESES were correlated with the WAI.

\section{Dimensions of emotional regulation found in the included studies}

Measures tapping emotional suppression or dampening (as measured by the CECS) were associated in some studies with more distress, more mood disturbances, more stress related symptoms, and more physical symptoms. However, other studies found that emotion suppression or dampening (as measured by the CECS) was not significantly related to psychological distress, autonomic physiology, or survival (Ando et al., 2011; Giese-Davis et al., 2008; Goodwin et al., 2004; Nakatani et al., 2014; Watson et al., 1999).Emotional dampening, as measured by the WCQ, was associated with longer survival times (Andreu et al., 2012; Classen et al., 1996; Reynolds et al., 2000; Schlatter et al., 2010; Tamagawa et al., 2013).

Measures tapping greater emotional expression were related to fewer depressive symptoms, greater life satisfaction, more posttraumatic growth, better perceived health, less psychological distress, fewer medical visits (when measured by the EACS). However, one study found that emotional expression (measured by the EACS) was not significantly related to 
depression, well-being, and breast cancer concerns (Batenburg et al., 2014). Emotional expression was also associated with more survival (when measured with the WCQ and the $\mathrm{R} / \mathrm{ED}$ ), and more distress (when measured with the COPE) (Batenburg et al., 2014; Cohen et al., 2011; Letho et al., 2006; Manne et al., 2004; Reynolds et al., 2000; Roussi et al., 2007; Stanton et al., 2000, 2012).

Emotional self-efficacy (that is confidence about emotion modulation and emotional expression) measured by the SESES-C was related to fewer mood disturbances, problems in medical interaction, and traumatic stress symptoms (Han et al., 2005; Koopman et al., 2002; Palesh et al., 2006). Self-efficacy of affect regulation, when measured by the CBI, was negatively related to difficulties in communicating with medical staff (Collie et al., 2005). More restraint and repression, as measured by the WAI-SF, was related to higher blood pressure and more problematic cortisol functioning (Giese-Davis et al., 2006, 2008). Acceptance, positive refocusing, and positive reappraisal, as measured by the CERQ, were associated with fewer depressive symptoms (Wang et al., 2014). Stronger efforts to control feelings (measured by the CFS) were associated with more psychological distress and higher mortality. Emotional constraint (measured by the MCSDS) was also related to higher mortality (Wheis et al., 2000). More detailed information regarding significant and non-significant results obtained with each scale can be seen in Table 2 .

(Insert Table 2 about here) 
A total of 12 studies evaluated the effects of psychosocial interventions on emotion regulation and emotional expression strategies for breast cancer patients. These psychosocial interventions were designed to specifically target emotion processes (e.g., expression of emotions, mindfulness and relaxation skills). Of the 12 intervention studies, 3 did not yield significant changes in emotional control or expression following intervention (Collie et al., 2007; Cousson-Gélie et al., 2011; Puig et al., 2006). The rest of the studies showed some adaptive change in measures of emotional control or expression.

Cameron et al. (2007) found that a group intervention significantly decreased participants' emotional suppression (measured with the CECS). Chan et al. (2006) found that an intervention emphasizing connections between mind and body significantly reduced emotional control (measured with the CECS). Giese-Davis et al. (2002) found that their supportiveexpressive group intervention (SEGT) significantly decreased emotional suppression and increased restraint of aggressive behavior (measured with the CECS and WAI-SF, respectively). In this study, SEGT was not found to be effective in improving emotional self-efficacy (measured with the SESES). In a separate study, Giese-Davis et al. (2006) found that a peercounseling intervention significantly increased cancer self-efficacy for newly diagnosed women (measured with the $\mathrm{CBI}$ ). Contrary to what was expected, this intervention increased repression of emotions (measured with the WAI-SF) for newly diagnosed women and increased emotional suppression (measured with the CECS) for peer counselors. As in the previous study by GieseDavis and colleagues emotional self-efficacy (measured with the SESES) was not affected by the intervention. Henderson et al. $(2012,2013)$ found that a mindfulness-based stress reduction (MBSR) intervention decreased emotional control (measured with the CECS). Van der Pompe et al. (2001) found that an experiential and existential group psychotherapy significantly decreased 
emotional control (measured with the CECS). Finally, Walker et al. (1991) found that a relaxation and guided imagery intervention significantly decreased emotional control (measured with the CECS).

Emotion regulatory factors have also been examined as moderators of treatment outcome in two studies. Manne et al. (2007) found that emotional expression and emotional processing (measured with the EACS) amplified the positive effects of a couple's group intervention on distress and well-being. In another study one dimension of alexithymia - externally oriented thinking (measured with the TAS) moderated the effect of an expressive writing intervention on cancer-related distress (i.e., individuals with fewer tendencies to focus their attention externally evidenced greater reductions in cancer-related distress (Jensen-Johansen et al., 2013).

One concern that is important to highlight is that changes in strategies used to regulate emotions were not tested as possible mediators of intervention efficacy in the already limited pool of studies evaluating the efficacy of psychological intervention in this population. Future intervention studies should examine this mediational role of emotion regulatory processes.

\section{Discussion}

It is important for both clinicians and researchers to be able to choose effective instruments to measure strategies that breast cancer patients use to regulate their emotions given the impact these strategies have on adaptation. In this systematic review we aimed to identify instruments that have been used to measure emotion regulatory strategies in women with breast cancer, to analyze the psychometric proprieties of these instruments, and to analyze the main results from studies using these instruments regarding emotion regulatory strategies. This systematic review can inform researchers' choices about scales to use to measure key aspects of 
individual differences in the ways in which women with breast cancer might regulate and express emotions.

We found that 16 different instruments have been used to measure the strategies used by breast cancer patients to regulate their emotions. The majority of the instruments were originally designed as general measures of coping and intended to assess individual differences in the use of specific coping strategies to regulate emotions. Overall, the most commonly used instruments tend to emphasize one's ability to control or dampen emotions (the CECS; the WAI-SF; the R/ED; the WCQ; the CFS; and the MCSDS); one's ability to express emotions (the EACS; the SESES-C; the EEQ; the CBI; the WCQ; the COPE; the ESDS; the AEEQ; and the BEQ); and one's ability to identify emotions (the EACS and the TAS). There are differences across these studies in what aspects of emotion regulation or strategies are believed to be the most important to tap. However, it is clear that the majority of studies have focused on strategies used to dampen the expression of negative emotions (i.e., suppression or inhibition of emotional expression). In fact, the CECS, which measures a general tendency to control or suppress the expression of negative emotions, has been the most commonly used scale in the context of research on breast cancer, followed by the EACS, which measures a tendency to engage (approach) the emotions elicited in stressful situations by acknowledging, understanding, and expressing them. In sum, the most commonly used instruments focus on tendencies to regulate the expression of negative emotions and include a wide range of specific strategies including conscious suppression and more automatic or defensive strategies (e.g., rationality, repression) that help individuals distance themselves from negative affect.

The focus on dampening emotional expression and on strategies that distance individuals from discomforting emotions is consistent with research on emotion regulatory processes outside 
of breast cancer that suggests there are costs to these strategies (e.g. Gross \& John, 2003; Waldinger \& Schulz, 2010). Some emotion researchers have found it helpful to characterize regulatory strategies in terms of whether they promote engagement with or distancing from negative affective experiences (Waldinger \& Schulz, 2010). Accumulating evidence provides support for the idea that emotional avoidance has adaptational costs and is also a risk factor for a range of psychological disorders (Aldao, 2013; Werner \& Gross, 2009; Waldinger \& Schulz, 2010). This view, however, has been challenged by researchers who argue that the adaptive consequences of regulatory strategies depend greatly on circumstances and on the specific person employing them (e.g., Bonanno \& Burton, 2013; Consedine, Magai, \& Bonanno, 2002; Schulz \& Lazarus, 2012).

In line with this argument, beliefs and goals that guide one's attempts to regulate emotions should be assessed in order to understand why a particular regulatory focus or strategy is being invoked and why it might be effective for one person or in one situation but not another. This is something that the majority of instruments employed to study emotion regulation or coping fail to do (Schulz \& Lazarus, 2012). Regulatory efforts to dampen emotion may be motivated by a number of personal goals. We think it is important to examine the motives that guide emotion regulation for women with breast cancer. For example, are the adaptational consequences similar if one is motivated to distance oneself from emotions to help get through a difficult medical procedure rather than to avoid upsetting an important provider of social support?

Also, another aspect that is understudied is the importance of examining emotion regulation in the context of close relationships, namely studying how intimate connections may shape emotion regulation efforts (and also how emotion regulation influences close 
relationships). In fact, none of the studies identified in this systematic review analyzed the role relational variables play in shaping the strategies used to regulate emotions when coping with breast cancer, and this is an aspect that needs further consideration.

Not surprisingly, the different instruments found in studies of breast cancer tapped different aspects of emotion regulation. We think it is important to consider multiple components of the emotion system when emotion regulatory processes are under study in order to better capture the complexity of emotion processes and the adaptive consequences of specific regulatory efforts. In addition to being focused on altering the three "output" channels of emotion (i.e., experiential, physiological, and behavioral), regulatory efforts can focus on choosing or modifying one's situation, altering one's attentional focus or changing one's understanding of the situation (Schulz \& Lazarus, 2012). Within each of these foci, there are a number of strategies that can be invoked to regulate emotions. From this perspective, it becomes clear why it might be difficult to find one instrument or construct that captures the "key" regulatory strategies. For this reason, theory and research questions should always inform the specific choice of instruments selected. Instruments that measure multiple regulatory strategies (e.g., broad coping indices) can be employed in more exploratory work.

This study focused on the structure or reliability of the measures in the identified studies including assessments of internal consistency (reported as a Cronbach alpha or as a KuderRichardson (KR20) coefficient alpha), test-retest reliability, and, in one study, the internal factor structure using confirmatory factor analysis (Wang et al., 2014). Of the 59 studies included, 23 (39\%) did not report any information regarding the reliability or factor structure of the instruments used. For the remaining studies, the majority of measures showed adequate internal consistency $(\alpha>$.70) and test-retest reliability ( $r>$.60) (Hunsley \& Mash, 2008). Only four 
studies reported poor internal consistency ( $\alpha$ 's between .32 and .59); the poor reliabilities were found for instruments used to tap emotional processing, cognitive emotion regulation strategies, coping strategies, and restraint (Giese-Davis et al., 2002; Hamana-Ray et al., 2012; Manne et al., 2004; Roussi et al., 2007). It is important to note that these poor reliabilities were also found for the same instruments or subscales (e.g., some CERQ and COPE subscales) when used with other populations. Continued indications of poor internal consistency raise concerns about whether these instruments are adequately assessing the construct in question. We recommend further validation studies for the scales that did not have adequate reliability or for which no information regarding their reliability was provided in studies of women with breast cancer.

It is important to highlight that there are reliable and valid measures widely used to assess emotion regulation and emotional expression in the larger field of psychology and medicine that have not been used in oncology studies. For example, we did not find any studies using the Emotion Regulation Questionnaire (Gross \& John, 2003) that is widely used to measure tendencies to use reappraisal and suppression and has been in existence for more than a decade. This questionnaire has presented good internal consistency and test-retest reliability ( $\alpha$ 's ranging between .73 and $.79 ; r=.86$ in Gross \& John, 2003). Another widely used measure, the Difficulties in Emotion Regulation Scale (DERS, Gratz \& Roemer, 2004), which focuses on several regulatory styles found to be associated with psychopathology and poor adaptation, was also not found in our search of studies of breast cancer. The DERS has demonstrated good internal consistency and test-retest reliability ( $\alpha$ 's ranging between .80 and $.89 ; r$ 's ranging between .58 and .88 in Gratz \& Roemer, 2004). We recommend that researchers integrate these well-vetted measures into studies of women with breast cancer. 
Finally, and as expected, there was a connection between the ways in which women with breast cancer regulate their emotions and different aspects of psychological adaptation to breast cancer. The fact that these associations were found across measures that overlapped in their intended constructs but differed in their specific content provides some reassurance about the validity of these measures. We cannot, however, conclude that these measures are assessing common constructs. We think that future studies should strive to evaluate the degree of redundancy among measures of emotion regulation-related constructs in order to evaluate if each instrument is assessing a distinct dimension or if a set of instruments can be integrated into a common measure (or measurement model) because they are assessing similar dimensions. Little information regarding intercorrelations among existing instruments is available, however the limited data available suggest that different instruments are assessing different constructs.

It is critical to recognize that the results obtained in the identified studies are influenced by a number of factors beyond the instruments used. Such factors include sample size, type of psychological intervention delivered, and the reliability and validity of other measures employed in the studies. Also, it is important to keep in mind that this systematic review was limited to English-language and peer-reviewed studies. This means that there is a risk of reporting bias and relevant studies may not have been included in this review.

The results of this systematic review provide guidance to researchers and clinicians interested in emotion regulatory processes for picking instruments with stronger psychometric properties that have been linked with specific psychosocial dimensions. The review also points to directions that may help improve the assessment of strategies used to regulate emotions, including the inclusion of the goals or motivations that are driving regulatory efforts. There is still much to learn about the nature of the relationship between emotion regulatory strategies and 
adaptation to breast cancer, but this review identifies strategies that both researchers and clinicians may want to focus on and consider in their work with women with breast cancer. Because there are a large number of strategies that can be invoked to regulate emotions and context is likely to influence the utility of these strategies it is important to keep studying and exploring which strategies can help women cope better with the challenges associated with breast cancer.

\section{References}

Adler, N. E., \& Page, A. E. (2008). Cancer care for the whole patient: Meeting psychosocial health needs. Washington DC: The National Academies Press.

Ando, N., Iwamitsu, Y., Kuranami, M., Okazaki, S., Nakatani, Y., Yamamoto, K., ... Miyaoka, H. (2011). Predictors of psychological distress after diagnosis in breast cancer patients and patients with benign breast problems. Psychosomatics, 52, 56-64. doi:10.1016/j.psym.2010.11.012

Andreu, Y., Galdón, M. J., Durá, E., Martínez, P., Pérez, S., \& Murgui, S. (2012). A longitudinal study of psychosocial distress in breast cancer: Prevalence and risk factors. Psychology \& Health, 27, 72-87. doi:10.1080/08870446.2010.542814

Austenfeld, J. L., \& Stanton, A. L., (2004). Coping through emotional approach: new look at emotion, coping, and health-related outcomes. Journal of Personality, 72, 1335-1363. doi:10.1111/j.1467-6494.2004.00299.x 
Bagby, R. M., Parker, J. D. A. \& Taylor, G. J. (1994). The twenty-item Toronto Alexithymia Scale-I. Item selection and cross-validation of the factor structure. Journal of Psychosomatic Research, 38, 23-32. doi:10.1016/0022-3999(94)90005-1

Barr, L. K., Kahn, J. H., \& Schneider, W. J. (2008). Individual differences in emotion expression: Hierarchical structure and relations with psychological distress. Journal of Social and Clinical Psychology, 27, 1045-1077.

Batenburg, A., \& Das, E. (2014). Emotional coping differences among breast cancer patients from an online support group: A cross-sectional study. Journal of Medical Internet Research, 16, e28. doi:10.2196/jmir.2831

Benjamin, L. S., \& Friedrich, F. J. (1991). Contributions of structural analyses of social behavior (SASB) to the bridge between cognitive science and a science of object relations. In:

Horowitz, M. J. (Ed.), Person schemas and maladaptive behavior (pp. 379-413). Chicago: University of Chicago Press.

Bonanno, G. A., \& Burton, C. L. (2013). Regulatory flexibility: An individual differences perspective on coping and emotion regulation. Perspectives on Psychological Science, 8(6), 591-612. doi: 10.1177/1745691613504116

Brajša-Žganec, A. Ivanović, D., Lipovčan, L. K. (2011). Personality traits and social desirability as predictors of subjective well-being. Psihologijske Teme, 20, 261-276.

Cameron, L. D., Booth, R. J., Schlatter, M., Ziginskas, D., \& Harman, J. E. (2007). Changes in emotion regulation and psychological adjustment following use of a group psychosocial 
support program for women recently diagnosed with breast cancer. Psycho-Oncology, 16, 171-80. doi:10.1002/pon. 1050

Campos, J. J., Frankel, C. B., \& Camras, J. M. (2004). On the nature of emotion regulation. Child Development, 75, 377-394.

Carver, C. S. (1997). You want to measure coping but your protocol's too long: Consider the Brief COPE. International Journal of Behavioral Medicine, 4, 92-100.

Carver, C. S., Scheier, M. F., \& Weintraub, J. K. (1989). Assessing coping strategies: A theoretically based approach. Journal of Personality and Social Psychology, 56, 267-283. doi.org/10.1037/0022-3514.56.2.267

Chan, C. L. W., Ho, R. T. H., Lee, P. W. H., Cheng, J. Y. Y., Leung, P. P. Y., Foo, W., ... Spiegel, D. (2006). A randomized controlled trial of psychosocial interventions using the psychophysiological framework for Chinese breast cancer patients. Journal of Psychosocial Oncology, 24, 3-26. doi:10.1300/J077v24n01_02

Classen, C., Koopman, C., Angell, K., \& Spiegel, D. (1996). Coping styles associated with psychological adjustment to advanced breast cancer. Health Psychology, 15, 434-437. doi.org/10.1037/0278-6133.15.6.434

Cohen, M. (2013). The association of cancer patients' emotional suppression and their self-rating of psychological distress on short screening tools. Behavioral Medicine, 39, 29-35. doi: $10.1080 / 08964289.2012 .731440$

Cohen, M., \& Numa, M. (2011). Posttraumatic growth in breast cancer survivors: A comparison of volunteers and non-volunteers. Psycho-Oncology, 20, 69-76. doi:10.1002/pon.1709 
Cole, P. M., Michel, M. K., \& Teti, L. O. (1994). The development of emotion regulation and dysregulation: A clinical perspective. Monographs of the Society for Research in Child Development, 59, 73-100.

Collie, K., Kreshka, M. A., Ferrier, S., Parsons, R., Graddy, K., Avram, S., .. Koopman, C. (2007). Videoconferencing for delivery of breast cancer support groups to women living in rural communities: A pilot study. Psycho-Oncology, 16, 778-872. doi:10.1002/pon.1145

Compas, B., C., Jaser, S. S., Dunbar, J. P., Watson, K. H., Bettis, A. H., Gruhn, M. A., \& Williams, E. K. (2013). Coping and emotion regulation from childhood to early adulthood: Points of convergence and divergence. Australian Journal of Psychology, 66, 71-81. doi: 10.1111/ajpy.12043

Consedine, N. S., Magai, C., \& Bonanno, G. A. (2002). Moderators of the emotion inhibitionhealth relationship: A review and research agenda. Review of General Psychology, 6, 204228.

Cousson-Gélie, F., Bruchon-Schweitzer, M., Atzeni, T., \& Houede, N. (2011). Evaluation of a psychosocial intervention on social support, perceived control, coping strategies, emotional distress, and quality of life of breast cancer patients. Psychological Reports, 108, 923-942. doi:10.2466/02.07.15.20.PR0.108.3.923-942

Crowne, D. P., \& Marlowe, D. (1964). The approval motive: Studies in evaluative dependence. New York: Wiley. 
Fernandez-Ballesteros, R., Ruiz, M. A., \& Garde, S. (1998). Emotional expression in healthy women and those with breast cancer. British Journal of Health Psychology, 3, 41-50. doi:10.1111/j.2044-8287.1998.tb00554.x

Folkman, S., \& Lazarus, R. S. (1980). An analysis of coping in a middle aged community sample. Journal of Health Social Behavior, 21, 219-239.

Garnefski, N., Kraaij, V., \& Spinhoven, P . H. (2002). Manual for the use of the Cognitive Emotion Regulation Questionnaire. Leiderdorp: DATEC.

Geenen, R., der Linden L., Lumley, M. A., Bijlsma, J. W., van Middendorp, H. (2012). The match-mismatch model of emotion processing styles and emotion regulation strategies in fibromyalgia. Journal of Psychosomatic Research, 72, 45-50. doi: 10.1016/j.jpsychores.2011.09.004

Giese-Davis, J., \& Spiegel, D. (2003). Emotional expression and cancer progression. In Richard J. D., Klaus, R. S. \& Hill H. G. (Eds.), Handbook of affective sciences (pp. 1053-1082). Oxford: Oxford University Press.

Giese-Davis, J., Bliss-Isberg, C., Carson, K., Star, P., Donaghy, J., Cordova, M. J., ... Spiegel, D. (2006). The effect of peer counseling on quality of life following diagnosis of breast cancer: An observational study. Psycho-Oncology, 15, 1014-22. doi:10.1002/pon.1037

Giese-Davis, J., Conrad, A., Nouriani, B., \& Spiegel, D. (2008). Exploring emotion-regulation and autonomic physiology in metastatic breast cancer patients: Repression, suppression, and restraint of hostility. Personality and Individual Differences, 44, 226-237.

doi:10.1016/j.paid.2007.08.002 
Giese-Davis, J., DiMiceli, S., Sephton, S., \& Spiegel, D. (2006). Emotional expression and diurnal cortisol slope in women with metastatic breast cancer in supportive-expressive group therapy: A preliminary study. Biological Psychology, 73, 190-198. doi:10.1016/j.biopsycho.2006.04.003

Giese-Davis, J., Koopman, C., Butler, L. D., Classen, C., Cordova, M., Fobair, P., ... Spiegel, D. (2002). Change in emotion-regulation strategy for women with metastatic breast cancer following supportive-expressive group therapy. Journal of Consulting and Clinical Psychology, 70, 916-925. doi:10.1037//0022-006X.70.4.916

Giese-Davis, J., Sephton, S. E., Abercrombie, H., Duran, R. E. F., \& Spiegel, D. (2004). Repression and high anxiety are associated with aberrant diurnal cortisol rhythms in women with metastatic breast cancer. Health Psychology, 23, 645-650. doi.org/10.1037/02786133.23 .6 .645

Goodwin, P. J., Ennis, M., Bordeleau, L. J., Pritchard, K. I., Trudeau, M. E., Koo, J., \& Hood, N. (2004). Health-related quality of life and psychosocial status in breast cancer prognosis: Analysis of multiple variables. Journal of Clinical Oncology, 22), 4184-4192. doi:10.1200/JCO.2004.12.091

Grassi, L., \& Cappellari, L. (1988). State and trait psychological characteristics of breast cancer patients. New Trends in Experimental and Clinical Psychiatry, 4, 99-109.

Grassi, L., \& Molinari, S. (1988). Pattern of emotional control and psychological reactions to breast cancer: A preliminary report. Psychological Reports, 62, 727-732. doi: 10.2466/pr0.1988.62.3.727 
Gratz, K.L. \& Roemer, E. (2004). Multidimensional assessment of emotion regulation and dysregulation: Development, factor structure, and initial validation of the difficulties in emotion regulation Scale. Journal of Psychopathology and Behavioral Assessment, 26, 4154. doi: 10.1023/B:JOBA.0000007455.08539.94

Graves, K. D., Schmidt, J. E., Bollmer, J., Fejfar, M., Langer, S., Blonder, L. X., \& Andrykowski, M. A. (2005). Emotional expression and emotional recognition in breast cancer survivors: A controlled comparison. Psychology \& Health, 20, 579-595.

doi: $10.1080 / 0887044042000334742$

Gross, J. J. (1989). Emotional expression in cancer onset and progression. Social Science and Medicine, 28, 1239-1248.

Gross, J. J. (1998). The emerging field of emotion regulation: An integrative review. Review of General Psychology, 2, 271-299.

Gross, J. J. (2001). Emotion regulation in adulthood: Timing is everything. Current Directions in Psychological Science, 10, 214-219. doi: 10.1111/1467-8721.00152

Gross, J. J., \& John, O. P. (19951997). Facets of emotional expressivity: Three self-report factors and their correlates. Personality and Individual Differences, 19, 555-568. doi:10.1016/0191-8869(95)00055-B

Gross, J.J., \& John, O.P. (2003). Individual differences in two emotion regulation processes: Implications for affect, relationships, and well-being. Journal of Personality and Social Psychology, 85, 348-362. doi.org/10.1037/0022-3514.85.2.348 
Hamama-Raz, Y., Perry, S., Pat-Horenczyk, R., Bar-Levav, R., \& Stemmer, S. M. (2012).

Factors affecting participation in group intervention in patients after adjuvant treatment for early-study breast cancer. Acta Oncologica, 51, 208-14. doi:10.3109/0284186X.2011.648339

Han, W. T., Collie, K., Koopman, C., Azarow, J., Classen, C., Morrow, G. R., ... Spiegel, D. (2005). Breast cancer and problems with medical interactions: relationships with traumatic stress, emotional self-efficacy, and social support. Psycho-Oncology, 14, 318-30. doi:10.1002/pon. 852

Heitzmann, C. A., Merluzzi, T. V., Jean-Pierre, P., Roscoe, J. A., Kirsh, K. L., \& Passik, S. D. (2011). Assessing self-efficacy for coping with cancer: Development and psychometric analysis of the brief version of the Cancer Behavior Inventory (CBI-B). Psycho-Oncology, 20,302-312. doi: 10.1002/pon. 1735

Henderson, V. P., Clemow, L., Massion, A. O., Hurley, T. G., Druker, S., \& Hebert, J. R. (2012). The effects of mindfulness-based stress reduction on psychosocial outcomes and quality of life in early-stage breast cancer patients: A randomized trial. Breast Cancer Research Treatment, 131, 99-109. doi:10.1007/s10549-011-1738-1

Henderson, V. P., Massion, A. O., Clemow, L., Hurley, T. G., Druker, S., \& Hébert, J. R. (2013). A randomized controlled trial of mindfulness-based stress reduction for women with earlystage breast cancer receiving radiotherapy. Integrative Cancer Therapies, 12, 404-413. doi: $10.1177 / 1534735412473640$ 
Hoyt, M. A., Stanton, A. L., Irwin, M. R., \& Thomas, K. S. (2013). Cancer-related masculine threat, emotional approach coping, and physical functioning following treatment for prostate cancer. Health Psychology, 32, 66-74. doi: 10.1037/a0030020

Hunsley, J., \& Mash, E. J. (2008). A guide to assessments that work. New York: Oxford University Press.

Iwamitsu, Y., Shimoda, K., Abe, H., Tani, T., Kodama, M., \& Okawa, M. (2003). Differences in emotional distress between breast tumor patients with emotional inhibition and those with emotional expression. Psychiatry and Clinical Neurosciences, 57, 289-294. doi:10.1046/j.1440-1819.2003.01119.x

Iwamitsu, Y., Shimoda, K., Abe, H., Tani, T., Okawa, M., \& Buck, R. (2005). Anxiety, emotional suppression, and psychological distress before and after breast cancer diagnosis. Psychosomatics, 46, 19-24. doi:10.1176/appi.psy.46.1.19

Iwamitsu, Y., Shimoda, K., Abe, H., Tani, T., Okawa, M., \& Buck, R. (2005). The relation between negative emotional suppression and emotional distress in breast cancer diagnosis and treatment. Health Communication, 18, 201-215. doi:10.1207/s15327027hc1803_1

Kaltsouda, A., Skapinakis, P., Damigos, D., Ikonomou, M., Kalaitzidis, R., Mavreas, V., Siamopoulos, K. C. (2011). Defensive coping and health-related quality of life in chronic kidney disease: A cross-sectional study. BMC Nephrology, 12, 28-37. doi: 10.1186/1471$2369-12-28$ 
King, L. A, \& Emmons, R. A. (1990) Conflict over emotional expression: Psychological and physical correlates. Journal of Personality and Social Psychology, 58, 864-877. doi.org/10.1037/0022-3514.58.5.864

Koopman, C., Butler, L. D., Classen, C., Giese-Davis, J., Morrow, G. R., Westendorf, J., ... Spiegel, D. (2002). Traumatic stress symptoms among women with recently diagnosed primary breast cancer. Journal of Traumatic Stress, 15, 277-287. doi:10.1023/A:1016295610660

Lagana, L., Chen, X., Koopman, C., Classen, C., Kimerling, R., \& Spiegel, D. (2002). Depressive symptomatology in relation to emotional control and chronic pain in persons who are HIV positive. Rehabilitation Psychology, 47, 402-414. doi: 10.1037//00905550.47 .4 .402

Lazarus, R. S. (1991). Emotion and adaptation. New York: Oxford University Press

Lehto, U.-S., Ojanen, M., Dyba, T., Aromaa, a, \& Kellokumpu-Lehtinen, P. (2006). Baseline psychosocial predictors of survival in localised breast cancer. British Journal of Cancer, 94, 1245-1252. doi:10.1038/sj.bjc.6603091

Lieberman, M. A., \& Goldstein, B. A. (2006). Not all negative emotions are equal: The role of emotional expression in online support groups for women with breast cancer. Psychooncology, 15, 160-168. doi: 10.1002/pon.932

Low, C. A., Stanton, A. L., \& Danoff-Burg, S. (2006). Expressive disclosure and benefit finding among breast cancer patients: Mechanisms for positive health effects. Health Psychology, 25, 181-189. doi: 10.1037/0278-6133.25.2.181 
Lundqvist, L. \& Ahlstrfm, G. (2006). Psychometric evaluation of the Ways of Coping Questionnaire as applied to clinical and nonclinical groups. Journal of Psychosomatic Research, 60, 485-493. doi: 10.1016/j.jpsychores.2005.08.019

Manna, G., Foddai, E., Di Maggio, M. G., Pace, F., Colucci, G., Gebbia, N., \& Russo, a. (2007). Emotional expression and coping style in female breast cancer. Annals of Oncology, Suppl 6, 77-80. doi:10.1093/annonc/mdm231

Manne, S., Ostroff, J. S., \& Winkel, G. (2007). Social-cognitive processes as moderators of a couple-focused group intervention for women with early stage breast cancer. Health Psychology,, 26, 735-744. doi:10.1037/0278-6133.26.6.735

Manne, S., Ostroff, J., Winkel, G., Goldstein, L., Fox, K., \& Grana, G. (2004). Posttraumatic growth after breast cancer: patient, partner, and couple perspectives. Psychosomatic Medicine, 66, 442-54.

Miotto, P., \& Preti, A. (2008). Suicide ideation and social desirability among school-aged young people. Journal of Adolescence, 31, 519-533. Doi: 10.1016/j.adolescence.2007.08.004

Moher D, Liberati A, Tetzlaff J, Altman DG, The PRISMA Group (2009). Preferred reporting items for systematic reviews and meta-analyses: The PRISMA Statement. Annals of Internal Medicine, 151, 65-94. doi: 10.7326/0003-4819-151-4-200908180-00136

Niles, A. N., Haltom, K. E., Mulvenna, C. M., Lieberman, M. D., \& Stanton, A. L. (2014). Randomized controlled trial of expressive writing for psychological and physical health: The moderating role of emotional expressivity. Anxiety, Stress \& Coping, 27, 1-17. doi: $10.1080 / 10615806.2013 .802308$ 
Palesh, O. G., Shaffer, T., Larson, J., Edsall, S., Chen, X.-H., Koopman, C., .. Parsons, R. (2006). Emotional self-efficacy, stressful life events, and satisfaction with social support in relation to mood disturbance among women living with breast cancer in rural communities. The Breast Journal, 12, 123-129. doi:10.1111/j.1075-122X.2006.00219.x

Politi, M. C., Enright, T. M., \& Wheis, K. L. (2006). The effects of age and emotional acceptance on distress among breast cancer patients. Supportive Care in Cancer, 15, 73-79. doi: 10.1007/s00520-006-0098-6

Puig, A., Lee, S. M., Goodwin, L., \& Sherrard, P. a. D. (2006). The efficacy of creative arts therapies to enhance emotional expression, spirituality, and psychological well-being of newly diagnosed Stage I and Stage II breast cancer patients: A preliminary study. The Arts in Psychotherapy, 33, 218-228. doi:10.1016/j.aip.2006.02.004

Reynolds, P., Hurley, S., Torres, M., Jackson, J., Boyd, P., \& Chen, V. W. (2000). Use of coping strategies and breast cancer survival: results from the Black/White Cancer Survival Study. American Journal of Epidemiology, 152), 940-949.

Ritz, T., \& Dahme, B. (1996). Repression, self-concealment and rationality/emotional defensiveness: The correspondence between three questionnaire measures of defensive coping. Personality and Individual Differences, 20, 95-102. Doi: 10.1016/01918869(95)00142-S

Roussi, P., Krikeli, V., Hatzidimitriou, C., \& Koutri, I. (2007). Patterns of coping, flexibility in coping and psychological distress in women diagnosed with breast cancer. Cognitive Therapy and Research, 31, 97-109. doi:10.1007/s10608-006-9110-1 
Schlatter, M. C., \& Cameron, L. D. (2010). Emotional suppression tendencies as predictors of symptoms, mood, and coping appraisals during AC chemotherapy for breast cancer treatment. Annals of Behavioral Medicine, 40, 15-29. doi:10.1007/s12160-010-9204-6

Schulz, M.S. \& Lazarus, R.S. (2012). Emotion regulation during adolescence: A cognitivemediational conceptualization. In P.K. Kerig, M.S. Schulz, \& S.T. Hauser (Eds.), Adolescence and beyond: Family processes and development (pp. 19-42). Oxford University Press.

Servaes, P., Vingerhoets, A.J.J.M., Vreugdenhil, G., Keuning, J. J., \& Broekhuijsen, A. M. (1999) Inhibition of emotional expression in breast cancer patients. Behavioral Medicine, 25, 23-27. doi:10.1080/08964289909596735

Smith, J. A., Lumley, M. A., \& Longo, D. J. (2002). Contrasting emotional approach coping with passive coping for chronic myofascial pain. Annual Behavioral Medicine, 24, 326-335. doi: 10.1207/S15324796ABM2404_09

Snell, W. E., Miller, R.S., \& Belk, S.S. (1988). Development of the emotional self-disclosure scale. Sex Roles,18, 59-76. doi: 10.1007/BF00288017

Spielberger, C. D., Krasner, S. S., \& Solomon, E. P. (1988) The experience, expression, and control of anger. In Janisse M. P. (Ed.), Individual differences, stress, and health psychology (pp. 89-108). New York: Springer-Verlag

Spokas, M., Luterek, J. A., \& Heimberg, R. G. (2009). Social anxiety and emotional suppression: The mediating role of beliefs. Journal of Behavior Therapy and Experimental Psychiatry, 40, 283-291. doi: 10.1016/j.jbtep.2008.12.004 
Stanton, A. L., \& Low, C. A. (2012). Dispositional and stressor-related emotion regulation in the context of a chronic, life-limiting stressor. Journal of Personality, 80, 287-311. doi:10.1111/j.1467-6494.2011.00732.x

Stanton, A. L., Danoff-Burg, S., Cameron, C. L., Bishop, M., Collins, C. a., Kirk, S. B., ... Twillman, R. (2000). Emotionally expressive coping predicts psychological and physical adjustment to breast cancer. Journal of Consulting and Clinical Psychology, 68, 875-882. doi:10.1037//0022-006X.68.5.875

Stanton, A. L., Kirk, S. B., Cameron, C. L., \& Danoff-Burg, S. (2000). Coping through emotional approach: Scale construction and validation. Journal of Personality and Social Psychology, 78, 1150-1169. doi.org/10.1037/0022-3514.78.6.1150

Tácon, A. M., Caldera, Y. M., \& Bell, N. J. (2001). Attachment style, emotional control, and breast cancer. Families, Systems, \& Health, 19, 319-326.

Taylor, G. J. (1994). The alexithymia construct: Conceptualization, validation, and relationship with basic dimensions of personality. New Trends in Experimental \& Clinical Psychiatry, $10,61-74$.

Terhorst, L., \& Mitchell, A. M. (2012). Ways of coping in survivors of suicide. Issues in Mental Health Nursing, 33, 32-38. Doi: 10.3109/01612840.2011.618584

Thompson, R. A. (1994). Emotion regulation: A theme in search of definition. In N. A. Fox (Ed.), The development of emotion regulation and dysregulation: Biological and behavioral aspects. Monographs of Society for Research in Child Development, 59, 25-52. 
Tjemsland, L., \& Søreide, J. A. (2004). Operable breast cancer patients with diagnostic delay-oncological and emotional characteristics. European Journal of Surgical Oncology, 30, 721-727. doi:10.1016/j.ejso.2004.05.005

Tjemsland, L., Søreide, J. a, \& Malt, U. F. (1995). Psychosocial factors in women with operable breast cancer. An association to estrogen receptor status? Journal of Psychosomatic Research, 39, 875-881. doi.org/10.1016/0022-3999(94)00029-2

Tjemsland, L., Soreide, J., Matre, R., \& Malt, U. (1997). Properative psychological variables predict immunological status in patients with operable breast cancer. Psycho-Oncology, 320, $311-320$.

Van der Pompe, G., Antoni, M. H., Duivenvoorden, H. J., Graeff, A., Simonis, R., van der Vegt, S., \& Heijnen, C. (2001). An exploratory study into the effect of group psychotherapy on cardiovascular and immunoreactivity to acute stress in breast cancer patients. Psychotherapy and Psychosomatics, 70, 307-318. doi:10.1159/000056271

Waldinger, R.J., \& Schulz, M.S. (2010). Facing the music or burying our heads in the sand?: Adaptive emotion regulation in midlife and late life. Research in Human Development, 7, 292-306. doi: 10.1080/15427609.2010.526527

Walker, L. G., Walker, M. B., Ogston, K., Heys, S. D., Ah-See, a K., Miller, I. D., ... Eremin, O. (1999). Psychological, clinical and pathological effects of relaxation training and guided imagery during primary chemotherapy. British Journal of Cancer, 80, 262-268. doi:10.1038/sj.bjc.6690349 
Wang, Y., Yi, J., He, J., Chen, G., Li, L., Yang, Y., \& Zhu, X. (2014). Cognitive emotion regulation strategies as predictors of depressive symptoms in women newly diagnosed with breast cancer. Psycho-Oncology, 23, 93-99. doi:10.1002/pon.3376

Watson, M., \& Greer, S. (1983). Development of a questionnaire measure of emotional control. Journal of Psychosomatic Research, 27, 299-305. doi:10.1016/0022-3999(83)90052-1

Watson, M., Greer, S., Rowden, L., Gorman, C., Robertson, B., Bliss, J., \& Tunmore, R. (1991). Relationships between emotional control, adjutsment to cancer and depression and anxiety in breast cancer patients. Psychological Medicine, 21, 51-57. doi.org/10.1017/S0033291700014641

Watson, M., Haviland, J., Greer, S., Davidson, J., \& Bliss, J. (1999). Influence of psychological response on survival in breast cancer: a population-based cohort study. The Lancet, 16, 1331-1336. doi:10.1016/S0140-6736(98)11392-2

Watson, M., Pettingale, K., \& Greer, S. (1984). Emotional control and autonomic arousal in breast cancer patients. Journal of Psychosomatic Research, 28, 467-474. doi:10.1016/00223999(84)90080-1

Weihs, K. L., Enright, T. M., \& Simmens, S. J. (2008). Close relationships and emotional processing predict decreased mortality in women with breast cancer: Preliminary evidence. Psychosomatic Medicine, 70, 117-124. doi: 10.1097/PSY.0b013e31815c25cf

Weihs, K. L., Enright, T. M., Simmens, S. J., \& Reiss, D. (2000). Negative affectivity, restriction of emotions, and site of metastases predict mortality in recurrent breast cancer. Journal of Psychosomatic Research, 49, 59-68. doi:10.1016/S0022-3999(00)00143-4 
Weinberger, D. A. (1990). The construct validity of the repressive coping style. In: Singer, J. L. (Ed.), Repression and dissociation: Implications for personality theory, psychopathology, and health (pp.337-386). Chicago: University of Chicago Press.

Werner, K.W. \& Gross, J.J. (2009) Emotion regulation and psychopathology: A conceptual framework. In Kring, A. \& Sloan, D. (Eds.), Emotion regulation and psychopathology. The Guilford Press, New York.

Zachariae, R., Pedersen, C. G., Jensen, A. B., Ehrnrooth, E., Rossen, P. B., \& von der Maase, H. (2003). Association of perceived physician communication style with patient satisfaction, distress, cancer-related self-efficacy, and perceived control over the disease. British Journal of Cancer, 88, 658-665. Doi: 10.1038/sj.bjc.6600798 


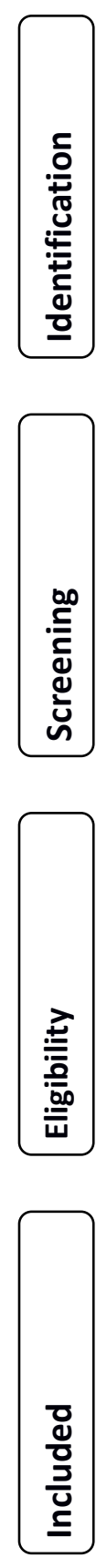

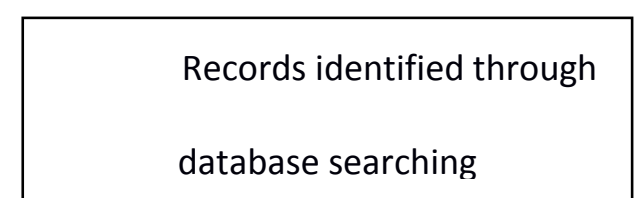

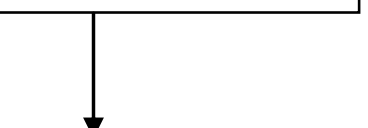

Records after duplicates removed
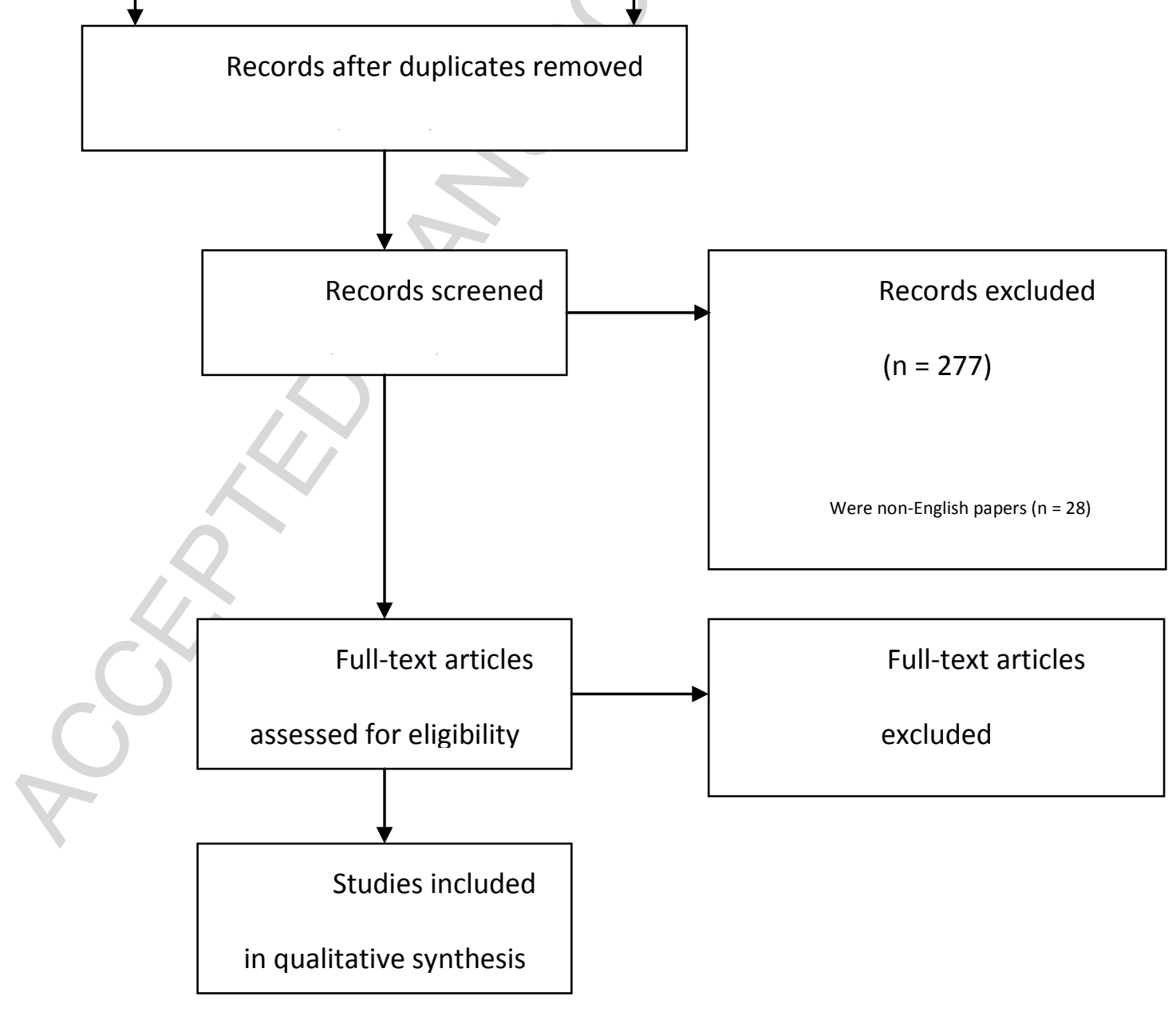

Figure 1. Flowchart of literature search. 


\section{Table 1}

Instruments Characteristics and Studies Using Each Instrument $(N=16)$

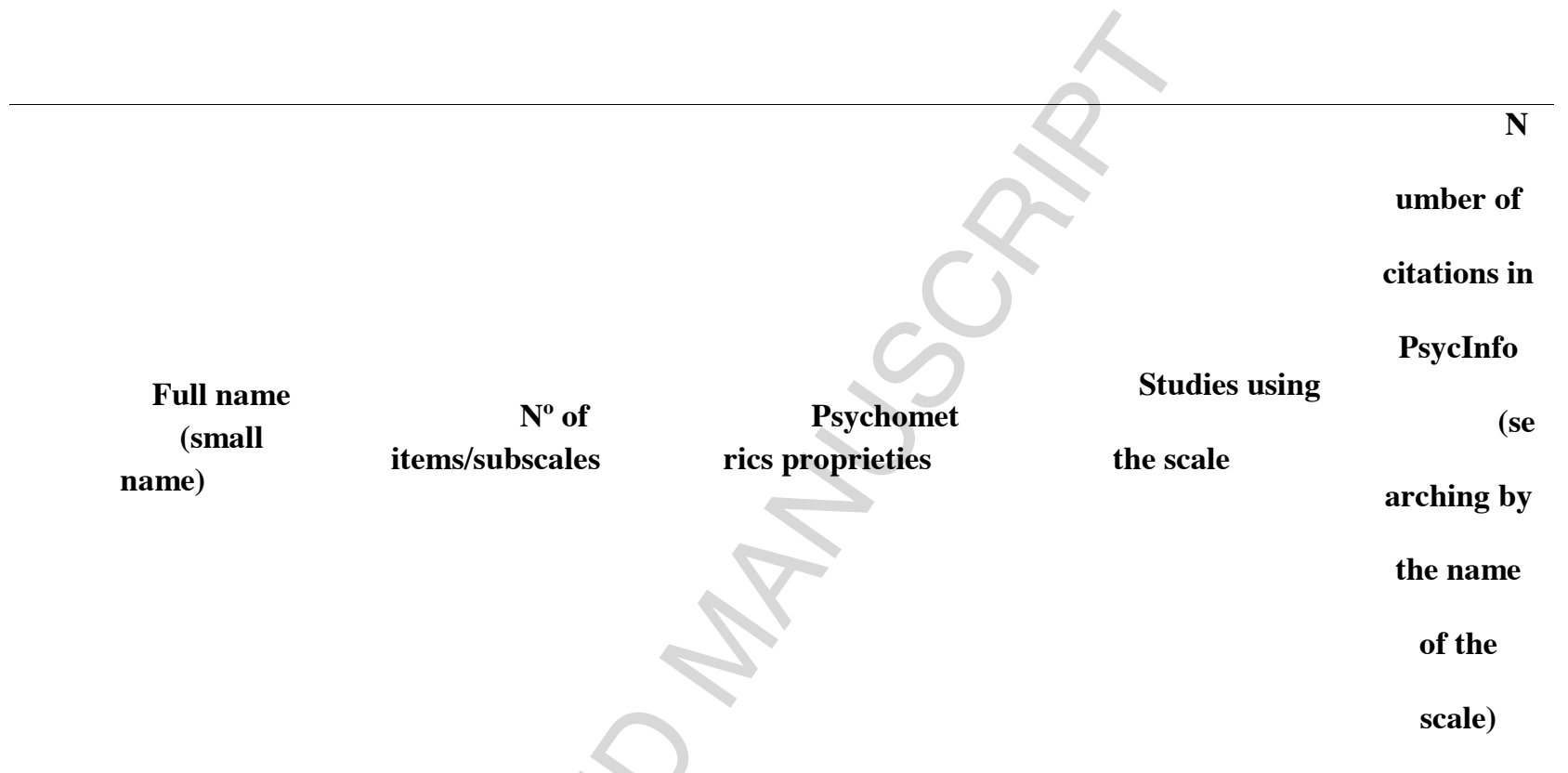

\section{2 studies: Ando et}

al., 2011; Andeu et al., 2012;

Cameron et al., 2007; Chan et al., 2006; Classen et al., 1996; Collie et al., 2007; Cousson-Gélie et al., 2011; Giese-Davis et al., 2002, 2006b, 2008; Goodwin et al., 2004; Grassi et al., 1988a, 1988b; Graves et al., 2005;

Information from 7 studies:

Emotional

The 8 items (2

Emotional Approach subscales: emotional Coping Scale

(EACS) expression and emotional processing)

20 items $(3$

The Toronto subscales: difficulty identifying feelings, difficulty describing
(TAS)

$\begin{aligned} \text { Alexithymia Scale } & \text { subscales: difficulty } \\ \text { (TAS) } & \text { identifying feelings, } \\ & \text { difficulty describing }\end{aligned}$

expression $\alpha$ range from 0.78 to 0.91 ;

Emotional

processing $\alpha$ range from 0.32 to 0.93

Test-retest $r=$ 0.72-0.73

2 studies did not report any information; Information from 4 studies: et al., 2014; Cohen et al., 2011;
Henderson et al., 2012, 2013; Iwamistu et al., 2003, 2005a, 2005b; Nakatani et al., 2014; Patrão et al., 2011; Schlatter et al., 2010; Tácon et al., 2001; Tamagawa et al., 2013; Tjemsland et al., 1995,1997,2004; Van der Pompe et al., 2001; Walker et al., 1999; Watson et al., 1984, 1991, 1999 Manne et al., 2004; Manne et al. 2007; Puig et al., 2006; Stanton et al., 2000, 2012

6 studies: Graves et al., 2005; Jensen-Johansen et al., 2013; Luminet et al., 2007; Mantani et al., 2007; Manna et al., 2007; Servaes et al., 1999 

feelings, and externally
orientated thinking)

The

Weinberg Adjustment Inventory - Short

Form

(WAI-SF)

The Stanford Emotional Selfefficacy Scale -

Cancer

(SESES-C)

The Cancer

Behavior Inventory

(CBI)

of Feeling Scale

(CFS)

The

Rationality/Emotional

Defensiveness

$(\mathrm{R} / \mathrm{ED})$

The

Ambivalence Over

experience of distress,
12 items $(2$

subscales: rationality and

emotional defensiveness)

subscales: subjective restraint, and repressivedefensiveness)

15 items (3

subscales: communicating emotions in relationships, focusing on the present moment, and confronting death and dying issues)

51 items $(6$

subscales: maintenance of activity and independence;

seeking and understanding medical information; stress management; coping with treatment-related sideeffects; accepting cancer/maintaining positive attitude; affective regulation; seeking support)

13 items

1 study did not report any information; Information

from 2 studies: $\alpha=0.92$

Test-retest $\mathrm{r}=$ 0.58

2 studies did not report any information; Information from 1 study: $\alpha=0.81,0.88$

Test-retest $\mathrm{r}=$ 0.81

Information from 2 studies;

Tamagawa et al., 2013

5 studies: Giese-

Davis et al., 2002, 2006b; Han et al., 2005; Koopman et al., 2002; Palesh et al., 2006;

3 studies: Collie et

al., 2005; Collie et al., 2007;

Giese-Davis et al.,

$2006 b$

3 study: Wheis et al., 2000; Politi et al., 2006; Wheis et al., 2008

3 studies: FernandezBallesteros et al., 1998; Graves et al., 2005; Letho et al., 2006

2 study: Algoe et al., 15 2011; Servaes et al., 1999 
Emotional Expression

Questionnaire

(AEEQ)

The

Cognitive Emotion

Regulation

Questionnaire

(CERQ)
The

Emotional

Expressiveness Questionnaire

(EEQ)

The Berkeley

Expressiveness

Questionnaire

(BEQ)

The COPE

(COPE)

The Emotion

Self-Disclosure Scale

(ESDS)

The Marlowe

Crowne Social

Desirability Scale

(MCSDS) $\alpha=0.87,0.94$

Information

from 2 studies:

Acceptance $\alpha$

$=0.63$; rumination $\alpha=$

0.59; positive refocusing

36 items $(9$

subscales: self-blame, acceptance, rumination, positive refocusing, refocus on planning, positive reappraisal, putting into perspective, catastrophizing, and otherblame)

$\alpha=0.67$; refocus on

planning $\alpha=0.69$;

positive reappraisal $=\alpha=$

0.70 ; putting into

Ray et al., 2012; Wang et al., 2014

perspective $\alpha=0.65$;

catastrophizing $\alpha=0.84$;

blame others $\alpha=0.68$

Other study:

$\alpha$ range from 0.75 to

0.96

CFA with

good fit indices: CFI

$=.92 ; \mathrm{NFI}=.90 ; \mathrm{IFI}$

$=.92 ;$ RMSEA $=.07$

1 study did not

report any information; Information from 1 study:

$\alpha=0.80$

16 items ( 3 subscales: negative expressivity, positive expressivity, and impulse strength)

60 items $(2$ groups: problem-focused strategies and emotionfocused strategies, including emotional expression)

40 items ( 8

subscales: depression, happiness, jealousy, anxiety, anger, calmness, apathy, fear, and pain)

33 items
Information

from 1 study: $\alpha>0.94$

Test-retest $\mathrm{r}=$ 0.86

Information from 1 study:

$\alpha$ range from 0.54 to 0.98 ( 2 bellow $0.60)$

Information from 1 study; $\alpha=0.93$ Information from 1 study: $\mathrm{KR} 20=0.80$ Test-retest $\mathrm{r}=$
2 studies: Graves et

al., 2005; Servaes et al., 1999

1 study: Stanton et al., 2012

1 study: Roussi et al., 2007

1 study: Servaes et al., 1999

1 study: Wheis et al., 2000 
53

0.88

28 items $(7$

The Ways of

Coping Questionnaire

- Modified

(WCQ-M) subscales: expressing emotions, suppressing emotions, wishful thinking, problem-solving, positive reappraisal, avoidance, and
The study did

not report any

information
1 study: Reynolds et

al., 2000

\footnotetext{
Note. $\alpha=$ Cronbach's coefficient alpha; KR20 = Kuder-Richardson's coefficient alpha; CFA = confirmatory factor analysis; CFI = comparative fit index; NFI = normed fit index; IFI = incremental fit index; RMSEA = root mean square error of approximation.
} 
Table 2

Main Results Obtained With Each Instrument

\begin{tabular}{|c|c|c|c|}
\hline Full name & $\begin{array}{l}\text { Significant } \\
\text { results* }\end{array}$ & $\begin{array}{l}\text { Non- } \\
\text { significant } \\
\text { results* }\end{array}$ & Main results \\
\hline $\begin{array}{l}\text { The Courtauld Emotional } \\
\text { Control Scale }\end{array}$ & 18 & 12 & $\begin{array}{l}\text { Emotional control was correlated with distress, anxiety, depression, } \\
\text { hostility, general emotions, health outcomes, helplessness, and } \\
\text { fatalism. Emotional control predicted mood disturbance, } \\
\text { depression, angry, coping strategies, physical symptoms, diagnostic } \\
\text { delay, and NK cells production. In five studies, psychological } \\
\text { intervention decreased emotional control. Three studies found } \\
\text { significant differences between women with BC and healthy } \\
\text { women in emotional control. Non-significant results: Emotional } \\
\text { control did not predict psychological distress, cortisol level, } \\
\text { autonomic physiology, ER level, immunological functioning, and } \\
\text { survival (two studies). In four studies, psychological interventions } \\
\text { did not change emotional control. One study found no differences } \\
\text { between women with BC and healthy women in emotional control. }\end{array}$ \\
\hline $\begin{array}{l}\text { The Emotional Approach } \\
\text { Coping Scale }\end{array}$ & 6 & 2 & $\begin{array}{l}\text { Emotional expression and emotional processing predicted more } \\
\text { post-traumatic growth, less depressive symptoms, more life } \\
\text { satisfaction, less psychological distress, better self-perceived health, } \\
\text { more vigor, and less medical visits. Also, moderated the effect of } \\
\text { couple intervention in depressive symptoms. Non-significant } \\
\text { results: In two studies interventions did not improve emotional } \\
\text { expression and emotional processing. }\end{array}$ \\
\hline $\begin{array}{l}\text { The Toronto Alexithymia } \\
\text { Scale }\end{array}$ & 4 & 2 & $\begin{array}{l}\text { One study found significant differences between women with BC } \\
\text { and healthy women in identifying feelings and describing feelings } \\
\text { to others. In one study alexithymia was predicted by higher levels } \\
\text { of anxiety and depression. In one study alexithymia predicted } \\
\text { higher levels of anxiety. In one study, alexithymia moderated the } \\
\text { effect of intervention on cancer-related distress. Non-significant } \\
\text { results: In one study alexithymia did not predict depression. Two } \\
\text { studies found no significant differences between women with BC } \\
\text { and healthy women in alexithymia. }\end{array}$ \\
\hline $\begin{array}{l}\text { The Weinberg Adjustment } \\
\text { Inventory }\end{array}$ & 4 & 1 & $\begin{array}{l}\text { Restraint and repression predicted blood pressure and diurnal slope } \\
\text { of cortisol. In one study intervention decreased restraint of negative } \\
\text { affects. When women with BC were compared with healthy women } \\
\text { they presented higher levels of restraint of negative affect. Non- }\end{array}$ \\
\hline
\end{tabular}




\begin{tabular}{|c|c|c|c|}
\hline & & & $\begin{array}{l}\text { significant results: In one study, psychological intervention did not } \\
\text { improve restraint neither repression. }\end{array}$ \\
\hline $\begin{array}{ll}\text { The Stanford } & \text { Emotional } \\
\text { Self-efficacy } & \text { Scale - } \\
\text { Cancer } & \end{array}$ & 2 & 3 & $\begin{array}{l}\text { Emotional self-efficacy predicted traumatic stress symptoms and } \\
\text { mood disturbance. }\end{array}$ \\
\hline \multicolumn{4}{|l|}{$\begin{array}{l}\text { Non-significant results: } \\
\text { In three studies, } \\
\text { psychological intervention } \\
\text { (online support } \\
\text { communities, peer } \\
\text { navigator program, and } \\
\text { group intervention) did not } \\
\text { improve emotional self- } \\
\text { efficacy. }\end{array}$} \\
\hline $\begin{array}{l}\text { The Cancer Behavior } \\
\text { Inventory }\end{array}$ & 2 & 1 & $\begin{array}{l}\text { Self-efficacy for affect regulation predicted difficulties } \\
\text { communicating with doctors and nurses. In one study, self-efficacy } \\
\text { improved after psychological intervention. Non-significant results: } \\
\text { Self-efficacy for affect regulation did not change after } \\
\text { psychological intervention. }\end{array}$ \\
\hline $\begin{array}{l}\text { The Control of Feeling } \\
\text { Scale }\end{array}$ & 2 & 1 & $\begin{array}{l}\text { Emotional acceptance predicted distress and increased mortality. } \\
\text { Non-significant results: Emotional acceptance alone did not } \\
\text { predict recurrence or survival. }\end{array}$ \\
\hline $\begin{array}{l}\text { The Rationality/Emotional } \\
\text { Defensiveness }\end{array}$ & 2 & & $\begin{array}{l}\text { Emotional expression predicted survival in patients with no local } \\
\text { metastases One study showed significant differences in emotional } \\
\text { expression between women with BC and healthy women. Non- } \\
\text { significant results: One study showed no differences between } \\
\text { women with BC and healthy women. }\end{array}$ \\
\hline $\begin{array}{l}\text { The Ambivalence Over } \\
\text { Emotional Expression } \\
\text { Questionnaire }\end{array}$ & 2 & - & $\begin{array}{l}\text { Women with BC presented more ambivalence over emotional } \\
\text { expression than healthy women. In one study, ambivalence over } \\
\text { emotional expression moderated the increase of social support. }\end{array}$ \\
\hline $\begin{array}{l}\text { The Cognitive Emotion } \\
\text { Regulation Questionnaire }\end{array}$ & 2 & - & $\begin{array}{l}\text { Cognitive emotion regulation strategies predicted the decision of } \\
\mathrm{BC} \text { patients to participate in group interventions and predicted } \\
\text { depressive symptoms in women with } \mathrm{BC} \text { ( } 1 \text { month later). }\end{array}$ \\
\hline $\begin{array}{l}\text { The Emotional } \\
\text { Expressivity } \\
\text { Questionnaire }\end{array}$ & - & 2 & $\begin{array}{l}\text { Non-significant results: Studies showed no differences between } \\
\text { women with } B C \text { and healthy women in emotional expressivity. }\end{array}$ \\
\hline $\begin{array}{l}\text { The Berkeley } \\
\text { Expressiveness } \\
\text { Questionnaire }\end{array}$ & 1 & - & $\begin{array}{l}\text { Dispositional emotional expressivity interacted with emotional } \\
\text { expression and emotional processing to predict depressive } \\
\text { symptoms and life satisfaction. }\end{array}$ \\
\hline The COPE & 1 & - & $\begin{array}{l}\text { Emotional expression was correlated with distress in post-surgery } \\
\text { and } 3 \text { months after surgery. }\end{array}$ \\
\hline $\begin{array}{l}\text { The Emotion Self- } \\
\text { Disclosure Scale }\end{array}$ & - & 1 & $\begin{array}{l}\text { Non-significant results: No differences between women with BC } \\
\text { and healthy women in emotion self-disclosure. }\end{array}$ \\
\hline $\begin{array}{l}\text { The Marlowe Crowne } \\
\text { Social Desirability Scale }\end{array}$ & 1 & - & Emotional constraint predicted increased mortality. \\
\hline $\begin{array}{l}\text { The Ways of Coping } \\
\text { Questionnaire }\end{array}$ & 1 & - & $\begin{array}{l}\text { Emotional expression predicted better survival and emotional } \\
\text { suppression predicted worse survival. }\end{array}$ \\
\hline
\end{tabular}

Note. Number of significant and non-significant results and not studies because one study can have a significant result

for one variable and a non-significant result for other variable. 


\section{Role of Funding Sources}

Funding for this study was provided by a $\mathrm{PhD}$ Scholarship from the Portuguese Foundation for Science and Technology (FCT) granted to the first author (SFRH/BD/84436/2012). FCT had no role in the study design, collection, analysis or interpretation of the data, writing the manuscript, or the decision to submit the paper for publication.

\section{Contributors}

Tânia Brandão and Rita Tavares conducted literature searches and data extraction. Tânia Brandão, Marc S Schulz, and Paula M Matos conducted the analysis and wrote the manuscript. All authors approved the final manuscript.

\section{Conflict of Interest}

The authors have no conflicts of interest to disclose. 
57

Highlights:

- Importance of emotion regulation and expression in breast cancer (BC) adaptation

- A systematic review of 59 studies tapping emotion regulation in BC context

- Sixteen different instruments are examined and related-results are discussed

- Clinical implications are discussed and suggestions for future research are offered 